\title{
CXCL12-Abundant Reticular Cell
}

National Cancer Institute

\section{Source}

National Cancer Institute. CXCL12-Abundant Reticular Cell. NCI Thesaurus. Code

C114786.

A fibroblast that expresses high levels of stromal cell-derived factor 1 (CXCL12), secretes type III collagen and forms processes that contact those of other similar cells to form a network of reticular fibers. These cells may play a role in hematopoietic stem cell maintenance. 